\title{
FOUCAULT E AS HETEROTOPIAS: ESPAÇO, PODER-SABER
}

\author{
Fabio Batista ${ }^{1}$ \\ Universidade Estadual do Oeste do Paraná (UNIOESTE) \\ https://orcid.org/0000-0003-2655-4514 \\ E-mail: fabiobatista1985@bol.com.br
}

\section{RESUMO:}

Este artigo trata do tema e problema da heterotopiaa partir do pensamento de Michel Foucault, noção essa pouco explorada por ele, no entanto, potencialmente profícua para o pensamento filosófico contemporâneo. Nele mostramos o que o filósofo francês chama de heterotopia (utopia localizada/espaço outro) e o modo como ela implica as noções de espaço, poder e saber. Para tanto abordamos textos foucaultianos especialmente da década de 1960 e 70. Interpretamos e nos reportamos assim às heterotopias que fazem parte dos estudos e trajetória de Foucault: fábrica-convento, cidade operária, asilo psiquiátrico, prisão e Universidade Experimental de Vincennes. Compreendemos que a prisão e seus mecanismos constituem o exemplo paradigmático de uma heterotopia moderna que ainda diz muito sobre nós. Isso indica, vale notar, a complexidade e ambivalência da noção foucaultiana de heterotopia, na medida em que esta pode abarcar uma série de dispositivos nem sempre afins: por vezes, então, uma instituição disciplinar e um espaço biopolítico, outras vezes, uma universidade experimental.

PALAVRAS-CHAVE: Foucault; Heterotopia; Poder-saber.

\section{FOUCAULT AND THE HETEROTOPIES: SPACE, POWER- KNOWLEDGE}

\begin{abstract}
:
This article deals with the theme and problem of heterotopy from Michel Foucault's thought, a notion that little explored by him, however, potentially useful for contemporary philosophical thought. In it we show what the French philosopher calls heterotopy (localized utopia / other space) and the way it implies the notions of space, power and knowledge. To this end, we approach Foucault texts especially from the 1960s and 70s. We interpret and report in this way to the heterotopias that are part of Foucault's studies and trajectory: factory-convent, working town, psychiatric asylum, prison and Experimental University of Vincennes. We understand that prison and its mechanisms are the paradigmatic example of a modern heterotopy that still says a lot about us. This indicates, it is worth noting, the complexity and ambivalence of the Foucauldian notion of heterotopy, insofar as it can encompass a series of devices not always related: sometimes, then, a disciplinary institution and a biopolitical space, other times, an experimental university.
\end{abstract}

KEYWORDS: Foucault; Heterotopia; Power-Knowledge.

\footnotetext{
${ }^{1}$ Doutor em Filosofia pela Universidade Estadual do Oeste do Paraná (UNIOESTE), Toledo - PR, Brasil.
} 


\section{Introdução}

Já de início podemos demarcar: a heterotopia ou utopia situada é o que Foucault chama de lugar real "fora de todos os lugares". Vejamos:

Há países sem lugar e histórias sem cronologias. [...]. Sem dúvida, essas cidades, esses continentes, esses planetas nasceram, como se costuma dizer, na cabeça dos homens, ou, na verdade, no interstício de suas palavras, nas espessuras de suas narrativas, ou ainda, no lugar sem lugar de seus sonhos no vazio de seus corações; numa palavra, é o doce gosto das utopias. No entanto, acredito que há - e em toda a sociedade - utopias que têm um lugar preciso e real, um lugar que podemos situar no mapa; utopias que têm um tempo determinado, um tempo que podemos fixar e medir conforme o calendário de todos os dias (2013a, p. 19).

Há, por exemplo, os jardins, os cemitérios, os asilos, as casas de tolerância, "há as prisões, as colônias de férias do Clube Mediterrâneo, e tantos outros" (2013a, p. 20). O filósofo francês procura, assim, demarcar o terreno da utopia e o da heterotopia, mostrando que essa última é uma utopia que encontrou ou tem um lugar no corpo sociopolítico ${ }^{2}$. Entre os tipos de heterotopia, vale mencionar as heterotopias de desvio, isto é, "os lugares que a sociedade dispõe em suas margens, nas paragens vazias que a rodeiam, são antes reservados aos indivíduos cujo comportamento é desviante relativamente à média ou à norma exigida". Esses lugares podem ser exemplificados com "as casas de repouso, as clínicas psiquiátricas, daí também, com certeza, as prisões" (FOUCAULT, 2013a, p. 22). Esta última, como veremos, pretende pôr o homem no campo da norma, isto é, fazer reinar a ordem. Assim, a prisão, mas também o asilo psiquiátrico, instituições disciplinares, cumprem essa função, ou são legitimadas a partir desse discurso reformador, argumenta Foucault (2009).

Também sobre a noção de heterotopia, acrescenta o filósofo francês: "As heterotopias possuem sempre um sistema de abertura e de fechamento que as isola em relação ao espaço circundante", constituindo uma população, o doente mental, o delinquente... "Em geral, não se entra em uma heterotopia como em um moinho, entra-se porque se é obrigado (as prisões, evidentemente), ou entra-se quando se foi submetido a ritos, a uma purificação" (FOUCAULT, 2013a, p. 26). A cura no asilo psiquiátrico, não compreende todo um rito de purificação, de tratamento moral? Além desse sistema de abrir e fechar que aparentemente torna a heterotopia uma "ilha" em meio a um campo social na qual não entramos e saímos facilmente, temos as "heterotopias que parecem abertas, nas quais, entretanto, só entram verdadeiramente os já iniciados". Isto é, "acredita-se que se teve acesso ao que há de mais simples, de mais exposto, quando, de fato, se está no coração do mistério" (FOUCAULT, 2013a, p. 27). Aqui, certamente, podemos falar da universidade e seus rituais, pois apenas parece aberta, ou ainda que aberta permaneça "fechada" àquele que não passou pela educação escolar, isto é, àquele que não passou por um sistema de avaliação que o permitiria ou não, e isto de acordo com o seu comportamento, dedicação, aprendizagem, se está ou não está na norma, tornar-se ou não um membro de sua comunidade. Todavia, veremos que a universidade de Vincennes, uma heterotopia, escapa desse sistema de aparente abertura e propõe um espaço de ilimitado exercício do pensamento.

\footnotetext{
2 Fazemos a ressalva de que, embora as noções de utopia e heterotopia possam aparecer juntas em seu pensamento, não pretendemos explorar o tema da utopia neste trabalho. Nosso propósito, como indicado no título deste artigo, é tratar da heterotopia.
}

BATISTA, Fabio. Foucault e as heterotopias: espaço, poder-saber. Griot : Revista de Filosofia, Amargosa - BA, v.20, n.2, p.116 , junho, 2020. 


\section{A fábrica-convento e a cidade operária}

Vemos nascer na modernidade uma série de heterotopias: a fábrica-convento e a cidade operária servem aqui como exemplos paradigmáticos desse crescimento dos mecanismos disciplinares sobre o corpo social da modernidade. Notamos que, com esse tipo de fábrica e cidade, o que importa é "prender" aquele que trabalha ao aparelho de produção, impor a rotina da vida de operário e, certamente, fazê-lo trabalhar. Desde essa perspectiva, as heterotopias compreendem uma face antinômade: uma fábrica-convento fazia trabalhar por meio da vigilância e controle de toda a existência. Do amanhecer ao anoitecer, o trabalhador permanecia sujeito a um regulamento que recortava o espaço, controlava o tempo determinando assim o ritmo das atividades: "levantar-se às $5 \mathrm{~h} 50$ para se arrumar, tomar café; fábrica das $6 \mathrm{~h} 10$ às 20h15, com intervalo de uma hora para as refeições; ceia, prece e cama às $21 \mathrm{~h}$ " (FOUCAULT, 2015, p. 185). Esse ordenamento não era muito diferente do regulamento da "Casa dos Jovens Detentos em Paris", de 1838, pois esse também determinava como devia começar o dia, o que fazer durante o dia e em qual horário dormir (FOUCAULT, 2009, p. 11-12-13). Na fábricaconvento ou na prisão até mesmo o domingo era objeto de regulamentação detalhada:

O domingo oferece-nos um espaço vazio a preencher; a suspensão dos trabalhos mecânicos leva naturalmente ao ensino moral e religioso, de acordo com a destinação deste dia. Mas, como não se pode empregar o dia inteiro nestas instruções que se tornariam, pela sua duração, inúteis e monótonas, é preciso variá-las com lições diferentes, às quais pode-se dar ainda um caráter moral e religioso pela escolha de trabalhos que os exercitam a ler, a copiar, a desenhar, o próprio cálculo pode facultar uma dupla instrução, servindo para resolver questões que desenvolvem os produtos do comércio, da agricultura, da indústria e do trabalho (BENTHAM, 1987, p. 221).

São "instituições que, no fundo, obedeciam aos mesmos modelos e aos mesmos princípios de funcionamento" (FOUCAULT, 2005a, p. 110). Diz Deleuze: "impor uma tarefa qualquer a uma multiplicidade humana qualquer" (2014, p. 78). Trata-se sempre da distribuição espacial e da vigilância, do controle do tempo e da correção.

A cidade operária também é disciplinar e opera a partir dos mesmos modelos e princípios na medida em que determina toda a existência de cada indivíduo que a habita e não apenas participa do esquema disciplinar, é também biopolítica, pois administra a vida da população. "Pode-se mesmo dizer que, na maioria dos casos, [...] os mecanismos disciplinares do corpo e os mecanismos regulamentadores da população são articulados um com o outro" (FOUCAULT, 2005, p. 299). A cidade operária "articula [...] mecanismos disciplinares de controle sobre o corpo [...] por sua quadrícula, pelo recorte mesmo da cidade, pela localização das famílias (cada uma numa casa) e dos indivíduos (cada um num cômodo) ". Aqui junto ao problema do controle que se deve operar pelo arranjo do espaço macro da cidade operária soma-se a organização do espaço micro, trata-se doravante do espaço da família em sua casa: "a família operária será fixada; será prescrito para ela um tipo de moralidade, através da determinação de seu espaço de vida, com uma peça que serve como cozinha e sala de jantar, o quarto dos pais e o quarto das crianças" (FOUCAULT, 2004b, p. 212).

Nesse caso, notamos como até mesmo as questões elementares da vida cotidiana são reguladas pela ordem disciplinar; e de um nível ao outro: "recorte, pôr indivíduos em visibilidade, normalização dos comportamentos, espécie de controle policial espontâneo que se exerce assim pela própria disposição espacial da cidade" (FOUCAULT, 2005, p. 299). A isso 
tudo se somam, de modo complementar, os mecanismos regulamentadores da biopolítica, os quais

[...] induzem comportamentos de poupança, por exemplo, que são vinculados ao habitat, à locação do habitat e, eventualmente, à sua compra. Sistemas de seguro-saúde ou de seguro-velhice; regras de higiene que garantem a longevidade ótima da população; pressões que a própria organização da cidade exerce sobre a sexualidade, portanto sobre a procriação; as pressões que se exercem sobre a higiene das famílias; os cuidados dispensados às crianças; à escolaridade, etc. (FOUCAULT, 2005, p. 299-300).

De um exemplo a outro, isto é, da fábrica-convento, celibatária e fechada ao exterior, à cidade operária aberta e recortada, o corpo-máquina para treinar e o corpo espécie para gerir. Assim, a modernidade implica, por um lado, a disciplina, a constituição da força produtiva (DELEUZE, 2014) e, por outro, a biopolítica, o "fazer viver" (FOUCAULT, 2005, p. 294).

\title{
"Uma máquina de curar"
}

O hospício também se enquadra nesse esquema disciplinar-biopolítico, com maior eficácia no exercício disciplinar. Na literatura ${ }^{3}$, esse lugar pôde tornar-se espaço de retiro e formação, todavia ele é, desde Esquirol e Pinel, "uma máquina de curar" (FOUCAULT, 1978, 2004) e espaço onde poder-corpo-saber-verdade podem se articular. Nesse contexto, Foucault considera que:

\begin{abstract}
No fundo da prática científica existe um discurso que diz: "nem tudo é verdadeiro; mas em todo lugar e a todo momento existe uma verdade a ser dita e a ser vista, uma verdade talvez adormecida, mas que no entanto está somente à espera de nosso olhar para aparecer, à espera de nossa mão para ser desvelada. A nós cabe achar a boa perspectiva, o ângulo correto, os instrumentos necessários, pois de qualquer maneira ela está presente aqui e em todo lugar" (FOUCAULT, 2004a, p. 113).
\end{abstract}

Todavia, nota o filósofo francês que nem sempre tivemos essa concepção da verdade. Temos "também [...] esta ideia que repugna à ciência e à filosofia: que a verdade, como o relâmpago, não nos espera onde temos a paciência de emboscá-la e a habilidade de surpreendêla, mas", e aqui aparece a outra concepção de verdade, "tem instantes propícios, lugares privilegiados, não só para sair da sombra como realmente para se produzir" (FOUCAULT, 2004a, p. 113). Desse modo, temos ao menos duas perspectivas acerca da verdade: uma verdade que passa pela descoberta-reencontro e pelo método; e uma verdade que "não é aquilo que é, mas aquilo que se dá: acontecimento" (FOUCAULT, 2004a, p. 114) ${ }^{4}$.

[Tal verdade] não é encontrada, mas sim suscitada: produção em vez de apofântica. Ela não se dá por mediação de instrumentos, mas sim provocada por rituais, atraída por meio de ardis, apanhada segundo ocasiões: estratégia e não método. Deste acontecimento que assim se produz impressionando aquele que o buscava, a relação não é do objeto ao sujeito de conhecimento. É uma relação ambígua, reversível, que luta

3 POMBO, Rocha. No hospício. Curitiba: Prefeitura Municipal de Curitiba, 1996. Esse romance de fim do século XIX mostra a experiência da formação de Fileto, o debate político sobre utopia - entre ele e o narrador - e a atitude antiutilitarismo de Fileto em um espaço não habitual para essas atividades, o hospício. Por que fileto está nessa instituição? "Monomania literária", eis a sua doença, classificação que indica uma crítica ao cientificismo classificador que faz parte do dispositivo psiquiátrico.

4 Sobre essa abordagem do problema da verdade, ver também: CASTRO, 2017; CANDIOTTO, 2010.

BATISTA, Fabio. Foucault e as heterotopias: espaço, poder-saber. Griot : Revista de Filosofia, Amargosa - BA, v.20, n.2, p.116 , junho, 2020. 
belicosamente por controle, dominação e vitória: uma relação de poder (FOUCAULT, 2004a, p. 114-115).

Foucault denomina essa última forma de verdade como verdade/prova e a primeira como verdade/constatação (FOUCAULT, 2004a, p. 116). Aquela é uma verdade produzida por um ritual e mecanismos de poder-saber. Foucault quer mostrar a existência e a coexistência desses dois tipos de verdade, claro, mas também e, sobretudo, que "a verdade/constatação, na forma do conhecimento talvez não passe de um caso particular da verdade/prova na forma do acontecimento; acontecimento que se produz como podendo ser de direito repetido sempre e em toda parte" (FOUCAULT, 2004a, p. 116). Diz ainda: "É esta forma singular de produção da verdade que pouco a pouco foi recobrindo as outras formas de produção da verdade e que, ou pelo menos, impôs a sua forma como universal" (FOUCAULT, 2004a, p. 116).

Aqui salta aos olhos a tese foucaultiana: a verdade constatação é apenas uma forma da verdade prova, ou seja, a descoberta, nossa concepção forte de verdade, é também acontecimento e, portanto, estratégia e contingência. No campo do direito, a tortura e o inquérito correspondem a essas duas formas da verdade, que às vezes até mesmo se complementam, respectivamente, verdade/prova e verdade/constatação (FOUCAULT, 2009). Como funciona a supremacia dessa última?

[Ela é] ritual de produção que toma corpo numa instrumentação e num método a todos acessíveis e uniformemente eficaz; saída que aponta um objeto permanente de conhecimento e que qualifica um sujeito universal de conhecimento (FOUCAULT, 2004a, p. 116).

Portanto, é por meio de seu caráter universal e demarcado que essa verdade pôde tomar a posição de forma única entre nós: ela tem método e tem definido aquilo que conhece e aquele que conhece. Elementos ímpares do pensamento filosófico e científico desde Descartes que a psiquiatria, em seu espaço institucional, como todo saber científico, reproduzirá, sem, contudo, deixar de lado toda a parafernália da verdade/prova. Assim, o hospício pode:

Permitir a descoberta da verdade da doença mental, afastar tudo aquilo que, no meio do doente, possa mascará-la, confundi-la, dar-lhes formas aberrantes, alimentá-la e também estimulá-la. Mais ainda que um lugar de desvelamento, o hospital, cujo modelo foi dado por Esquirol, é um lugar de confronto. A loucura, vontade perturbada, paixão pervertida, deve aí encontrar uma vontade reta e paixões ortodoxas. [...] Um processo de oposição, de luta e dominação (FOUCAULT, 2004a, p. 121-122).

Isso porque, de acordo com Foucault, a ordem disciplinar exercida no hospício está na base do saber médico psiquiátrico, "já que, sem essa disciplina, sem essa ordem, sem esse esquema prescritivo de regularidades não é possível ter uma observação exata", poderíamos dizer: sem a ordem disciplinar não há a verdade da doença (FOUCAULT, 2006, p. 4). Importante para a produção da verdade, a disciplina também é "condição da cura permanente" (FOUCAULT, 2006, p. 5): assim, "condição do olhar médico" (FOUCAULT, 2006, p. 4) e da verdade sob seu objeto, é também condição da operação terapêutica: "essa transformação a partir da qual alguém considerado doente deixa de ser doente" (FOUCAULT, 2006, p. 5). "Logo", diz Foucault, "a condição da relação com o objeto e da objetividade do conhecimento do médico e a condição da operação terapêutica são as mesmas: a ordem disciplinar" (2006, p. 5). Há, nessa heterotopia, "uma instância única que é, ao mesmo tempo, interior ao asilo e o 
ponto a partir do qual se fazem a repartição e a dispersão disciplinares dos tempos, dos corpos, dos gestos, dos comportamentos, etc" (FOUCAULT, 2006, p. 5).

Essa instância, [...] que faz com que essa ordem seja uma ordem sempre derivada de uma relação não recíproca de poder, pois bem, é evidentemente a instância médica que, como vocês vão ver, funciona como poder muito antes de funcionar como saber [e verdade] (FOUCAULT, 2006, p. 5).

A disciplina na base do saber e da cura psiquiátrica encontra no médico uma espécie de ponto de partida, ou melhor, um ponto de passagem e ordenação da circulação e exercício do poder disciplinar. Vale notar, assim, que o médico não deve ser compreendido como fonte de poder ou de origem do poder psiquiátrico, mas uma instância dessa batalha, um lugar acima na hierarquia que lhe possibilita "uma relação não recíproca de poder". "Mas", diz Foucault, "esse poder do médico, claro, não é o único poder que se exerce; porque, no asilo como em toda parte, o poder nunca é aquilo que alguém detém, tampouco é o que emana de alguém”, pois, "o poder não pertence nem a alguém nem, aliás, a um grupo; só há poder porque há dispersão, intermediações, redes, apoios recíprocos, diferenças de potencial, defasagens, etc." (2006, p. 7).

Há no hospício funções nessa rede de poder: do vigilante, passando pelo servente até o médico novamente em uma espécie de circuito do poder no espaço asilar. A proximidade que o servente tem com o doente - proximidade porque ambos se encontram próximos na hierarquia da ordem disciplinar do hospício - é de extrema importância, pois "o servente vai relatar o que é digno de ser relatado ao vigilante, que relatará ao médico" (FOUCAULT, 2006, p. 8). Desse modo, o hospício se fez espaço de saber e verdade, assim como de terapia e cura. A terapêutica e a cura aparecem como domínio daquele que é tido como doente mental, pois é por meio de uma "ortopedia moral" (FOUCAULT, 2006, p. 12) que a cura se torna possível.

De acordo com Foucault, a operação terapêutica é uma cena de enfrentamento. No final das contas, todo saber e ação terapêutica e até mesmo a cura passam pela ordem interna do espaço asilar: a rede de olhares, o controle, a sanção. Por exemplo, Foucault descreve uma cena incompleta - de enfretamento físico - do domínio que o vigilante deve exercer sobre o "alienado" (FOUCAULT, 2006, p.13)5. E também nos apresenta uma cena de cura de um jovem que não come porque acredita que assim terá a salvação eterna. De que modo intervém a operação terapêutica? Por meio de uma cena para assustar: é o medo e a ameaça que intervêm aqui, com "olhos de fogo, um tom de voz fulminante", um tal cidadão Pussin, "um grupo de serventes à sua volta"... e assim segue a descrição da cena, tudo isso para provocar o "alienado" a tomar a decisão de se alimentar, e se alimentar regularmente novamente e assim abandonar violência astuciosa e súbita" (FOUCAULT, 2006, p. 13).

BATISTA, Fabio. Foucault e as heterotopias: espaço, poder-saber. Griot : Revista de Filosofia, Amargosa - BA, v.20, n.2, p.116 , junho, 2020. 
seus "preconceitos religiosos" (FOUCAULT, 2006, p. 13-14)6. Para qualificar essa cena de cura, Foucault fala de batalha, choque de duas vontades, vitória.

Essa relação de força tem por primeiro efeito suscitar uma segunda relação de força dentro, de certo modo, do próprio doente, já que se trata de suscitar um conflito entre a ideia fixa a que o doente se agarrou e o medo da punição - um combate que provoca outro. E todos os dois, quando a cena é bem-sucedida, devem remeter a uma vitória, a vitória de uma ideia sobre a outra, que deve ser ao mesmo tempo a vitória da vontade do médico sobre a do doente. [E mais, é ao final dessa cena que a verdade se manifesta]: o que é importante nessa cena é que acaba se dando um momento em que a verdade se manifesta; é o momento em que o doente reconhece que sua crença na necessidade de jejuar para alcançar sua salvação era errada e delirante [...]. Em suma, é o próprio relato do doente que constitui, nessa cena em que até agora a verdade nunca interveio, o momento em que a verdade se manifesta (FOUCAULT, 2006, p. 14-15).

Espaço de articulação de poder-saber, de cena e batalha, verdade e cura: tudo isso se passa no hospício, no interior dessa instituição-heterotopia onde a psiquiatria cresceu e desde então não parou de se expandir sobre o corpo sociopolítico. "O mundo é um grande hospício", diz Foucault (2011a, p. 308), “onde os governantes são os psicólogos [e psiquiatras] e o povo, os pacientes", isto é, o poder político moderno assumiu uma função terapêutica: de "correção" ou "ortopedia social" (FOUCAULT, 2011a, p. 307). Assim, a psiquiatria - e os saberes de radical psi - é apropriada pelo Estado, ou seja, os dispositivos psiquiátricos, que nascem no espaçohospício, são postos ao serviço do poder político estatal. Desde essa perspectiva, a psiquiatria tem uma face disciplinar-institucional e outra biopolítica-estatal ${ }^{7}$.

\section{$[\ldots]$ "Pena das sociedades civilizadas" $[\ldots]$}

Uma outra heterotopia moderna é assim definida: "pena das sociedades civilizadas" (ROSSI apud FOUCAULT, 2009, p. 218). Trata-se da prisão que doravante ocupa o lugar do suplício no âmbito do direito penal. Ela vem de muitos lugares ${ }^{8}$, forma máxima do poder disciplinar que se expande sobre a justiça penal. Dois princípios a fundamentam: primeiro, ela é privação de liberdade, e "como não seria a prisão", argumentam seus defensores, "a pena por

6 "A cena de cura é uma cena complexa. Eis um exemplo famoso no Tratado médico-filosófico de Pinel. Era um rapaz que era 'dominado por preconceitos religiosos' e que pensava que para alcançar sua salvação devia 'imitar as abstinências e as macerações dos antigos anacoretas', isto é, rejeitar não apenas, é claro, todos os prazeres da carne, mas também qualquer alimentação. Um belo dia ele recusa com mais dureza que de costume uma sopa que lhe servem. ' $O$ cidadão Pussin se apresenta de noite à porta da sua cela com um aparato ['aparato' no sentido do teatro clássico, é claro; M.F.] próprio para assustar, olhos em fogo, um tom de voz fulminante, um grupo de serventes à sua volta, armados com fortes correntes, que agitam ruidosamente; põem uma sopa junto do alienado e dão-lhe a ordem mais clara de tomá-la durante a noite, se não quiser sofrer os mais cruéis tratamentos; retiram-se e deixam-no no mais penoso estado de flutuação, entre a ideia da punição que o ameaça e a perspectiva apavorante dos tormentos da outra vida. Após um combate interior de várias horas, a primeira ideia prevalece e ele se determina a ingerir sua alimentação. Submetem-no depois disso a um regime destinado a restaurá-lo; o sono e as forças retornam gradativamente, assim como o uso da razão, e ele escapa desse modo a uma morte certa. Foi durante a sua convalescença que ele confessou suas agitações cruéis e suas perplexidades durante aquela noite da sua provação'. Temos aí uma cena importantíssima, creio eu, em sua morfologia geral" (FOUCAULT, 2006, p. 13-14).

7 Apenas para apontar uma tese que "renova" a tese foucaultiana: de acordo com Byung-Chul Han, "a imposição de disciplina corporal cede lugar à otimização mental. Assim, o neuro-enhancement distingue-se fundamentalmente das técnicas psiquiátricas disciplinares" (2015, p. 35).

8 Ela vem da moral quaker (moral de controle e vigilância, da comunidade religiosa homônima, diante da ferocidade da legislação penal inglesa do século XVII que previa a pena capital para muitos tipos de crime) e da carta régia (internar para curar o indivíduo imoral) (FOUCAULT, 2005a). Vem também, certamente, da utopia de Bentham: o panóptico (FOUCAULT, 2009, p. 236).

BATISTA, Fabio. Foucault e as heterotopias: espaço, poder-saber. Griot : Revista de Filosofia, Amargosa - BA, v.20, n.2, p.116 , junho, 2020. 
excelência numa sociedade em que a liberdade é um bem que pertence a todos da mesma maneira e ao qual cada um está ligado por um sentimento universal e constante?" (FOUCAULT, 2009, p. 218). Segundo, é um "aparelho para transformar os indivíduos"9 "Como não seria a prisão imediatamente aceita?". Pois ela é apenas a maximização dos mecanismos de outros aparelhos: "a prisão: um quartel um pouco estrito, uma escola sem indulgência...", diz Foucault (2009, p. 219).

Vale ressaltar que aqui Foucault está no nível da análise dos dispositivos sobre esse novo modo de punir que perfaz a modernidade. Isto é, Foucault ainda não opera uma avaliação sobre eles, apenas os descreve e mostra como eles justificaram a incorporação da prisão ao Judiciário. A contribuição de Foucault foi não apenas de mostrar os fundamentos que justificaram essa apropriação, mas também mostrar que a "reforma da prisão é mais ou menos contemporânea da própria prisão. Ela é como seu programa" (FOUCAULT, 2009, p. 220). Isto é, "não devemos então conceber a prisão, seu 'fracasso' e sua reforma mais ou menos bem aplicada como três tempos sucessivos" (FOUCAULT, 2009, p. 257), mas, diz Foucault, como sempre ou quase sempre, tais tempos são simultâneos.

Desde o começo, perceberam-se os inconvenientes da prisão, pois ela não transformava indivíduos de forma a reeducá-los, não produzia "homens virtuosos" (FOUCAULT, 2003a, p. 134), mas, pelo contrário, formava, sobretudo, a delinquência. Foucault mostra os pontos sobre os quais se articulam as críticas e os projetos de reforma da prisão e, surpreendentemente, vemos que são os mesmos há mais de dois séculos. Resumamos primeiramente as críticas: "as prisões não diminuem a taxa de criminalidade"; "a detenção provoca a reincidência"; "a prisão não pode deixar de fabricar delinquentes"; "a prisão [...] favorece a organização de um meio delinquente"; "as condições dadas aos detentos libertados condenam-nos fatalmente à reincidência"; "a prisão fabrica indiretamente delinquentes, ao fazer cair na miséria a família do detento" (FOUCAULT, 2009, p. 251-254). "Ora", diz Foucault, "a essas críticas, a resposta foi invariavelmente a mesma" $(2009$, p. 255), a prisão como remédio da prisão: a referência ao programa; e a formulação da reforma: a prisão deve tornar-se aquilo que ainda não é, mas que já, desde o começo, deveria ter sido: uma máquina para a reforma do indivíduo que cometeu um crime $^{10}$.

Os princípios da reforma são "as sete máximas universais da boa 'condição penitenciária"": 1. princípio da correção, isto é, a transformação ou recuperação do condenado; 2. princípio da classificação: distribuição dos detentos de acordo com o seu perfil: qual é sua idade? Que tipo de crime cometeu? Que tipo de correção aplicar a ele?; 3. princípio da modulação das penas, ou seja: modular o tempo de detenção de acordo com o comportamento do condenado; 4. princípio do trabalho como obrigação e como direito: o qual serve para a transformação dos detentos e "progressiva socialização" dos mesmos; 5. princípio da educação penitenciária: "a instrução geral" do detento que deve servir para a sua "melhora"; 6. princípio

\footnotetext{
9 Transformar por meio do isolamento, o qual punha a questão: que tipo de isolamento praticar? Absoluto ou relativo? O primeiro tipo corresponde ao sistema de encarceramento da Filadélfia e o segundo ao sistema de Auburn. Transformar também pelo trabalho: "a utilidade do trabalho penal? Não é um lucro; nem mesmo a formação de uma habilidade útil; mas a constituição de uma relação de poder, de uma forma econômica vazia, de um esquema da submissão individual e de seu ajustamento a um aparelho de produção" (FOUCAULT, 2009, p. 230). A isso Foucault denomina de penitenciário: isto é, a transformação do indivíduo privado de liberdade por meio de mecanismos de controle, vigilância e correção: "suplemento disciplinar em relação ao jurídico" (2009, p. 234).

10 “O que deve ser uma prisão? Um lugar onde se privam da liberdade os indivíduos que dela abusaram, para prevenir novos crimes por parte deles e para dissuadir os outros pelo terror do exemplo. É, além disso, uma casa de correção onde se deve propor a reforma dos costumes das pessoas detidas, a fim de que seu retorno à liberdade não seja uma infelicidade nem para a sociedade, nem para elas próprias" (BENTHAM, 1987, p. 201).
}

BATISTA, Fabio. Foucault e as heterotopias: espaço, poder-saber. Griot : Revista de Filosofia, Amargosa - BA, v.20, n.2, p.116 , junho, 2020. 
do controle técnico da detenção: trata-se da importância de manter na prisão um pessoal com saber técnico especializado: o médico, o psicólogo; 7. princípio das instituições anexas que estabelece não apenas a vigilância, mas também a assistência aos detentos, durante e depois da pena $^{11}$ (FOUCAULT, 2009, p. 255-257)12. "Palavra por palavra, de um século a outro, as mesmas proposições fundamentais se repetem. E são dadas a cada vez como a formulação enfim obtida, enfim aceita de uma reforma até então sempre fracassada"13 (FOUCAULT, 2009, p. 257).

Por que a repetição da mesma crítica e da mesma reforma há tanto tempo? A prisão fracassou? Que tipo de fracasso é esse? Foucault responde com outra questão a essas questões: “O pretenso fracasso não faria parte do funcionamento da prisão?" (FOUCAULT, 2009, p. 257). E dá a essa questão uma resposta afirmativa: sim, o que chamamos de fracasso pode ser compreendido como um sucesso. Mas vale perguntar: de que modo é um êxito o que parece ser o seu contrário? Para Foucault:

a prisão e, de uma maneira geral, sem dúvida, os castigos, não se destinam a suprimir as infrações; mas antes a distingui-las, a distribuí-las, a utilizá-las; que visam não tanto tornar dóceis os que estão prontos a transgredir as leis, mas que tendem a organizar a transgressão das leis numa tática geral das sujeições. A penalidade seria então uma maneira de gerir as ilegalidades, de riscar limites de tolerância, de dar terreno a alguns, de fazer pressão sobre outros, de excluir uma parte, de tornar útil outra, de neutralizar estes, de tirar proveito daqueles. Em resumo, a penalidade não "reprimiria" pura e simplesmente as ilegalidades; ela as "diferenciaria", faria sua "economia" geral. E se podemos falar de uma justiça de classe não é só porque a própria lei ou a maneira de aplicá-la servem aos interesses de uma classe, é porque toda a gestão diferencial das ilegalidades por intermédio da penalidade faz parte desses mecanismos de dominação. Os castigos legais devem ser recolocados numa estratégia global das ilegalidades. $O$ "fracasso" da prisão pode sem dúvida ser compreendido a partir daí (2009, p. 258).

A penalidade de detenção fabrica a delinquência como uma forma de ilegalismo fechado em si, como ameaça à sociedade e à classe trabalhadora e torna possível que esse ilegalismo funcione política e economicamente a favor da classe dominante. É por isso que, de acordo com Foucault, a prisão permanece a pena por excelência: ela não diminui a criminalidade, ela não reabilita o indivíduo, mas torna a delinquência útil (FOUCAULT, 2009). Quais, portanto, as vantagens do uso da delinquência? Ela é um tipo de ilegalismo que pode ser controlado: "localizando os indivíduos, infiltrando-se no grupo, organizando a delação mútua" (FOUCAULT, 2009, p. 263). Além disso, pode ser orientada para formas de ilegalidade menos perigosas politicamente. Todavia, diz Foucault: "essa ilegalidade concentrada, controlada e desarmada é diretamente útil" (FOUCAULT, 2009, p. 263). Desse modo, a delinquência, "ilegalidade dominada", não é apenas posta à margem: por exemplo, no que diz respeito à economia e ao comércio ilegal e ao lucro que deles advém:

11Bentham diz: em liberdade o indivíduo "está tão acostumado à obediência que se tornará, sem dúvida, um bom soldado" (BENTHAM, 1987, p. 222). Ou pode-se torná-lo colono no caso em que não possua colônia.

12 Foucault mostra essa permanência dos princípios da reforma da prisão recorrendo a documentos dos séculos XIX e XX, isto é, por comparação de textos que propõem a reforma dela.

13 "Os maiores rigores das prisões, dos ferros, dos calabouços só são empregados para impedir a fuga dos prisioneiros. A reforma dos costumes tem sido negligenciada, seja por uma indiferença bárbara, seja porque desistiu-se de esperar resultados. Algumas tentativas neste sentido não foram felizes. Alguns projetos foram abandonados porque demandavam somas consideráveis. As prisões são, ainda hoje, lugares infectos e horríveis, escolas de todos os crimes e amontoados de todas as misérias, que só conseguiríamos visitar, horrorizados" (BENTHAM, 1987, p. 201).

BATISTA, Fabio. Foucault e as heterotopias: espaço, poder-saber. Griot : Revista de Filosofia, Amargosa - BA, v.20, n.2, p.116 , junho, 2020. 
Os tráficos de armas, os de álcool nos países de lei seca, ou mais recentemente os de droga, mostrariam da mesma maneira esse funcionamento da "delinquência útil"; a existência de uma proibição legal cria em torno dela um campo de práticas ilegais, sobre o qual se chega a exercer controle e a tirar um lucro ilícito por meio de elementos ilegais, mas tornados manejáveis por sua organização em delinquência. Esta é um instrumento para gerir e explorar as ilegalidades (FOUCAULT, 2009, p. 265).

Diz ainda Foucault: "é também um instrumento para a ilegalidade que o próprio exercício do poder atrai a si”. Aqui ele se refere, compreendemos, ao poder estatal-políticojudiciário, à delinquência como meio de ação do poder de Estado, pois, "[...] todo um funcionamento extralegal do poder foi em parte realizado pela massa de manobra constituída pelos delinquentes: polícia clandestina e exército de reserva do poder". Em suma, “[...] pode-se dizer que a delinquência, solidificada por um sistema penal centrado sobre a prisão, representa um desvio de ilegalidade para os circuitos de lucro e de poder ilícitos da classe dominante" (FOUCAULT, 2009, p. 265).

Nesse circuito foi e é indispensavelmente a polícia: o controle exercido por ela tem como objeto "[...] a massa dos acontecimentos, das ações, dos comportamentos, das opiniões" (FOUCAULT, 2009, p. 202). Para tanto, torna tudo visível, enquanto ela mesma deve ser invisível: um olhar sem rosto transforma o campo social em campo de percepção; assim, a polícia põe em funcionamento uma vigilância hierárquica. Foucault nos fala do exemplo parisiense que formou uma rede de olhares hierarquizados:

[...] os 48 comissários, os 20 inspetores, depois os 'observadores', pagos regularmente, as "moscas abjetas" retribuídos por dia, depois os denunciadores, qualificados de acordo com a tarefa, enfim as prostitutas. E essa incessante observação deve-se acumular numa série de relatórios e registros; [...] o que é assim registrado são comportamentos, atitudes, virtualidades, suspeitas - uma tomada de contas permanente do comportamento dos indivíduos (2009, p. 202).

Uma coisa é importante para a nossa abordagem: nessa vigilância hierárquica, as moscas abjetas, os denunciadores e as prostitutas (a delinquência tornada útil) estão em um dos limites, próximo à população; é a partir deles que aquilo que acontece nesse nível pode chegar mais facilmente à outra ponta-limite desse esquema hierárquico, a polícia, "olho do governo" (FOUCAULT, 2009). Cabe notar que, assim, de acordo com o filósofo francês:

Prisão e polícia formam um dispositivo geminado; sozinhas elas realizam em todo o campo das ilegalidades a diferenciação, o isolamento e a utilização de uma delinquência. Nas ilegalidades, o sistema polícia-prisão corresponde a uma delinquência manejável. Esta, com sua especificidade, é um efeito do sistema; mas torna-se também uma engrenagem e um instrumento daquele. De maneira que se deveria falar de um conjunto cujos três termos (polícia-prisão-delinquência) se apoiam uns sobre os outros e formam um circuito que nunca é interrompido. A vigilância policial fornece à prisão os infratores que esta transforma em delinquentes, alvo e auxiliares dos controles policiais que regularmente mandam alguns deles de volta à prisão (FOUCAULT, 2009, p. 267) ${ }^{14}$.

14 Sobre a prisão no Brasil: MENDES, Igor. A pequena prisão. São Paulo: n-1 edições, 2017. O autor é um jovem ativista que permaneceu preso de dezembro de 2014 a junho de 2015 . Vale citar uma passagem do referido livro: "Por que falo em 'pequena prisão'? Exatamente porque, iludidos com uma sociedade autoproclamada 'livre', vivemos na verdade em uma imensa, cada vez maior, prisão. [...] O que chamamos de prisão, a cadeia, é apenas uma fração da prisão maior em que vivemos" (MENDES, 2017, p. 34). 
Juntamente com essas preocupações teóricas de Foucault sobre poder-saber e heterotopia, há também uma atividade de intervenção direta no campo social: o GIP - Grupo de informação sobre as prisões, cujo objetivo era abrir um espaço de problematização sobre o dispositivo punitivo-prisão ${ }^{15}$. Assim, fazer "a história do presente", diz ele em 1975 (FOUCAULT, 2009) e agir politicamente, captar o intolerável (FOUCAULT, 2013), faz parte da compreensão do que vem a ser a filosofia ${ }^{16}$. Posteriormente, no fim da década de 1970, Foucault, ao se aproximar do texto de Kant, "Resposta à pergunta: o que é esclarecimento?", passa a falar de "ontologia do presente", de "atitude crítica" e de "atitude de modernidade" e explícita de que a questão que nos importa é compreender os limites do nosso tempo e a ultrapassagem possível desses limites. Essas duas perspectivas são inquestionavelmente complementares: o pensamento de Foucault é uma atitude crítica radical que busca, além de compreender, curtocicuitar o corpo social, transformá-lo? Parece que sim. Não apenas o filósofo e intelectual assim fizeram, mas também o Foucault professor assim quis.

\section{Vincennes: "inaugurar uma utopia educacional"}

Universidade ou o "Centre Experimental de Vincennes" (ERIBON, 1990 p. 187): um espaço-tempo de formação aberto a experimentações do pensamento e da existência? Sim, do qual falaremos especialmente do Departamento de Filosofia no qual Foucault foi professor.

Vale lembrar que, de acordo com Kant, a universidade iluminista era composta por faculdades e estas se dividiam em superior e inferior: "três Faculdades Superiores e a Faculdade inferior" (1993, p. 21). Entre as primeiras, "contam-se somente aquelas em cujas doutrinas o governo está interessado, se elas devem ser constituídas assim ou assado ou publicamente expostas" - são as faculdades de teologia, direito e medicina; "pelo contrário", diz Kant, "aquela que unicamente tem de velar pelo interesse da ciência diz-se inferior, porque pode lidar com as suas proposições como lhe aprouver" (1993, p. 21). Esta última é a faculdade de filosofia. Essa "arquitetura" da universidade tem, nos parece, um fim político, pois, diz Kant, "o que mais interessa ao governo é o meio de ele manter a mais forte e duradoira influência sobre o povo e desta natureza são os objectos das Faculdades superiores" (1993, p. 21). Todavia, de

15 O GIP (1971-1972) reuniu pensadores, intelectuais e ativistas franceses de esquerda. Entre eles estavam, Gilles Deleuze, Daniel Defert e o próprio Foucault. O objetivo do grupo era atuar junto àqueles que de algum modo tinham a experiência da prisão - ex-detentos, familiares de presos, detentos, funcionários das prisões - usando questionários e publicando-os posteriormente para que a opinião pública pudesse ter acesso ao que acontecia atrás dos muros dessa instituição penal. Os resultados mais importantes talvez tenham sido os debates e a visibilidade que essa instituição passou a ter e a proliferação de outros grupos de informação em outros setores constituindo uma rede, descentralizada, mas articulada, de problematização de questões sociopolíticas.

16 Desse modo, também Foucault o fez em suas histórias da psiquiatria e psicologia, medicina, ciências humanas, criminologia. Diz Foucault em 1983: "pode-se perfeitamente fazer a história do que a razão experimenta como sua necessidade, ou, sobretudo, do que as diferentes formas de racionalidade dão como lhes sendo necessário, e encontrar as redes de contingências de onde isso emergiu; o que não quer dizer, porém, que essas formas de racionalidade sejam irracionais; isso quer dizer que elas repousam sobre um fundamento de prática humana e de história humana, e porque essas coisas foram feitas, elas podem, com a condição de que se saiba como foram feitas, ser desfeitas" (FOUCAULT, 2000, p. 325-326).

Em 1979, Foucault fala do tipo de história que praticava: "Muito simplesmente, não sou historiador. E não sou romancista. Pratico uma espécie de ficção histórica. [...] Escrevi muito sobre loucura, no início dos anos 60 - fiz uma história do nascimento da psiquiatria. Sei muito bem que aquilo que fiz é, de um ponto de vista histórico, parcial e exagerado. [...] Mas meu livro teve efeito sobre a maneira como as pessoas percebem a loucura. Portanto, meu livro e a tese que nele desenvolvo têm uma verdade na realidade de hoje. Procuro provocar uma interferência entre a nossa realidade e o que sabemos de nossa história passada. Se tenho sucesso, essa interferência produzirá reais efeitos em nossa história presente. Minha esperança é que meus livros tomem a sua verdade uma vez escritos, e não antes" (2003b, p.321). 
acordo Genis, a faculdade de filosofia, nessa divisão, "é, em definitivo, a possibilidade do exercício filosófico" (2015, p. 98), ou, como diz Kant:

Importa absolutamente que, na universidade, se dê ainda à comunidade erudita uma Faculdade que, independente das ordens do governo quanto às suas doutrinas, tenha a liberdade não de proferir ordens, mas, pelo menos, de julgar todas as que têm a ver com o interesse científico, com o da verdade, em que a razão deve estar autorizada a publicamente falar; porque, sem semelhante liberdade, a verdade não viria à luz (para dano do próprio governo) (1993, p. 22).

Talvez o Departamento de Filosofia do "Centre Experimental de Vincennes" tenha levado ao limite e além do limite essa liberdade de pensamento, preocupado não apenas em problematizar e analisar, entre eruditos, as proposições da ciência, a verdade ou falsidade dos seus enunciados, propôs novos temas e problemas filosóficos nos quais a própria razão e o saber, o estatuto da ciência e a própria universidade entram em questão.

O centro universitário de Vincennes nasceu no momento das insurreições de 1968 - o chamado Maio de $68^{17}$ - e Foucault foi encarregado de convidar os professores do Departamento de Filosofia. Convida então Deleuze, Judith Miller, Alain Badiou, Jacques Rancière, François Châtelet. A universidade abre as portas em dezembro de 1968 e os primeiros cursos têm início em janeiro de 1969 (ERIBON, 1990). Constituída pelos expoentes do pensamento francês, essa universidade "tinha uma missão particular, a de inaugurar uma utopia educacional" (CAPONI, 2014, p. 6). Interpretamos que a expressão "inaugurar uma utopia educacional" pode compreender a noção de heterotopia. Esta é, como lembra Gallo, "lugares outros que existem nos lugares mesmos, ao mesmo tempo, [capazes de] experimentar espaços outros dentro dos próprios espaços instituídos". Esse "inaugurar" e "experimentar" no espaço universitário passavam por "estratégias pedagógicas e acadêmicas" específicas, tais como "a interdisciplinaridade, a falta de distinção entre cursos magistrais e trabalhos tutoriais, serviços iguais entre professores, inscrição aberta e livre para não graduados e acolhimento irrestrito para os estudantes estrangeiros" (CAPONI, 2014, p. 6).

No entanto, logo se inicia o embate político-institucional, pois o Departamento de Filosofia não parece de acordo com aquilo que se esperava que fosse um lugar de ensino e pesquisa filosófica. Vejamos: os "cursos definidos para os anos de 1968-69: 'Revisionismoesquerdismo', por Jacques Rancière; 'Ciências das formações sociais e filosofia marxista', por Étienne Balibar; 'Revoluções culturais', por Judith Miller" (ERIBON, 1990, p. 192) e outros mais com a mesma perspectiva. Foucault ofertou cursos sobre o discurso da sexualidade, o fim da metafísica, a epistemologia das ciências da vida, Nietzsche. $O$ ministro da Educação Olivier Guichard (substituto de Faure) denuncia o caráter "marxista-leninista" dos cursos dados em filosofia. Isso leva-o a considerar, que diante dessa especificidade de temas, os estudantes desse departamento não teriam seus diplomas reconhecidos pelo ministério da Educação e, consequentemente, não poderiam, posteriormente, lecionar.

Foucault não demora a lhe responder em entrevista coletiva, questionando suas medidas de restrição ao Departamento de Filosofia. Eribon menciona que Foucault partiu desta questão: "sendo a vocação de Vincennes estudar o mundo contemporâneo, explica, como o departamento

17 “Após as revoltas de maio de 68, o governo desejava afastar as manifestações estudantis do coração de Paris, estimulando a abertura de uma universidade experimental em um dos locais mais bonitos, mas também mais afastados do centro da cidade: o Bosque de Vincennes. No mês de outubro de 1968, Faure [ministro da Educação] tinha apresentado uma lei de reforma do ensino superior. Numa manobra decididamente demagógica, afirmava-se que, a partir desse momento, as Universidades estariam regidas pelos princípios de autonomia, pluridisciplinaridade e participação dos usuários" (CAPONI, 2014, p. 7). 
de filosofia poderia deixar de ser uma reflexão sobre a política?" (1990, p. 193). E, acrescenta Foucault: "que nos digam de modo claro o que é a filosofia e em nome do que - de qual texto, de qual critério ou qual verdade - rejeitam o que fazemos" (2011, p. 184). Nessa mesma direção, ainda questiona: "por que esse cordão de isolamento? O que a filosofia (a cadeira de filosofia) tem de tão precioso e de tão frágil para que seja preciso protegê-la com tantos cuidados? E o que há de tão perigoso em Vincennes?" (2011, p. 184-185).

Aqui estamos diante dos problemas próprios da filosofia e desta com o ensino e a política: o que é a filosofia? Qual curso pode ser dado quando se está na faculdade de filosofia? A filosofia pode ser perigosa? Os detratores de Vincennes, e não apenas o governo, também questionavam os cursos dessa universidade, dizendo "para que serve um curso de filosofia?". Vocês, professores de filosofia ou filósofos, falam de tudo, criticam tudo, criticam a própria sociedade que os alimenta, "já é tempo de os alunos não mais perderem o tempo deles. Suprimamos toda essa mixórdia" (FOUCAULT, 2011, p. 186). Esse era o tom da retórica daqueles para quem Vincennes era um reduto de esquerdistas.

Derrida pensava, três décadas depois do início de Vincennes, em uma "universidade sem condição", de liberdade incondicional de pesquisa e discussão, onde se pode dizer tudo, mesmo se for apenas "a título de ficção e de experimentação do saber", com "o direito de dizê-lo publicamente, de publicá-lo" (2003, p. 21). Mas reconhece que, "por ser absolutamente livre, a Universidade é uma cidadela exposta" (2003, p. 21). Esse parece ter sido um pouco o dilema de Vinncenes. Reflete Foucault: "desde o começo, recebemos inteira liberdade. Evidentemente, poderíamos ter tentado fazer rodeios com essa liberdade" (2011, p. 189). Mas não, não fizeram rodeios e logo começaram a incomodar. Essa foi a armadilha de Vinncennes, diz ele (2011).

Diante da irrupção da força estudantil em 1968, o governo francês a maneja para as margens de Paris e espera que lá ela não faça muito barulho. Foucault disse que era possível recorrer a duas formas de hipocrisia para evitar a exasperação do governo e, assim, permanecer dentro de um quadro reformista aceito. A primeira seria "modificar as formas pedagógicas do ensino (constituir grupos de estudo, dar certa liberdade de intervenção aos estudantes) sem nada mudar no conteúdo" (2011, p. 189). A segunda:

modificar o conteúdo; introduzir no programa autores como Nietzsche, Freud, Marx etc., mantendo, porém, a forma tradicional do ensino (dissertações, exames, controles diversos). Recusamos uma e outra dessas conciliações. Tentamos fazer a experiência de uma liberdade não digo total, mas tão completa quanto possível numa universidade como a de Vincennes (2011, p. 189).

Nesse modo de encarar o ensino de filosofia, os professores e os estudantes definiram então dois eixos de estudos: a política e a ciência, pois lhes pareciam as duas regiões "mais ativas e fecundas" (FOUCAULT, 2011, p. 190). Para eles, se tratava de pensar "não mais quais eram os limites do saber (ou seus fundamentos), mas quais seriam os que sabem? Como se faz a apropriação e distribuição do saber?" Ou seja, questões sobre o saber e o poder, da relação entre um e outro, "questões mais teóricas". "Como um saber pode obter um lugar na sociedade, desenvolver-se nela, mobilizar recursos e pôr-se a serviço de uma economia? Como o saber se forma numa sociedade e nela se transforma?" Mas também questões “mais críticas, sobre o que é a Universidade (as faculdades e os liceus) como lugar aparentemente neutro, onde um saber objetivo é suposto distribuir-se equitativamente" (FOUCAULT, 2011, p. 189). São essas questões filosóficas? São esses problemas que podem ter lugar no departamento de filosofia? É 
isso filosofia? Foucault acreditava que sim e por tal motivo os colocava em sua docência e pesquisa. Pouco tempo antes de morrer, já longe de Vincennes há mais de uma década, dizia:

O que é filosofar hoje em dia - quero dizer, a atividade filosófica - senão o trabalho crítico do pensamento sobre o próprio pensamento? Se não consistir em tentar saber de que maneira e até onde seria possível pensar diferentemente em vez de legitimar o que já se sabe? (FOUCAULT, 1998, p. 13).

Em última instância, podemos dizer que a compreensão do filósofo sobre o que é a filosofia determinará - de certo modo - os rumos do seu pensamento e escritos. Para Foucault, a filosofia não é mais contemplação ou elaboração de sistema, mas uma atitude que, sendo assim, imbrica vida e pensamento. É também problematização do presente por meio de uma investigação histórico-filosófica cujo objetivo, se desejável, é a transformação desse presente e de nós. A universidade de Vincennes pôde ser o espaço onde Foucault e demais filósofos colocaram essa perspectiva em ação dando vida a uma filosofia que pensa a heterogeneidade, os dispositivos e as práticas.

\section{Considerações finais}

Heterotopias? Esta é uma noção foucaultiana que raramente apareceu em seus escritos, duas ou três vezes ao todo. Nosso objetivo foi estudar e compreender como essa noção pode funcionar para uma leitura de certos temas em Foucault. Isto é, a partir do termo heterotopia usá-lo para mostrar como podemos interpretar certas instituições e espaços estudados pelo filósofo francês como um lugar outro ou utopia localizada. Mostrando como estes espaços outros articulam poder e saber, seja no campo da psiquiatria ou do direito penal ou ainda em uma universidade. Vale dizer que, ainda que aparentemente à margem, estas heterotopias ditaram em parte o ritmo da nossa modernidade, nascem juntas a esta e em certa medida não podemos compreendê-la sem considerá-las. Por um lado, umas favorecem o controle social característico da modernidade, o qual Foucault denomina de disciplinar e biopolítico. Por outro, abre um espaço para uma liberdade radical, como no exemplo de Vincennes. 


\section{Referências}

BENTHAM, Jeremy; DUMONT, Etienne. "Panóptico - Memorial sobre um novo princípio para construir casas de inspeção e, principalmente, prisões". Revista Brasileira de História: Instituições. São Paulo, v. 7, n. 14, p.199-229, março/agosto de 1987.

CANDIOTTO, César. O Pensamento do Mesmo: entre utopias e heterotopias. Doispontos, Curitiba, São Carlos, v. 14, n. 1, p. 169-179, abr. de 2017.

CAPONI, Sandra. Foucault e a universidade: entre o governo dos outros e o governo de si mesmo. Cadernos IHU ideias, São Leopoldo, v. 12, n. 211, p. 320, 2014.

CASTRO, Edgardo. Los dispositivos foucaultianos. Fermentario, Montevideo, v. 2, n. 11, 2017.

DELEUZE, Gilles. El poder: curso sobre Foucault. Trad. Pablo Ires, Sebastián Puente. Ciudad Autónoma de Buenos Aires: Cactus, 2014. Tomo II.

ERIBON, Didier. Michel Foucault (1926-1984). Trad. Hildegard Feist. São Paulo: Companhia das Letras, 1990.

FOUCAULT, Michel. A sociedade punitiva: curso no Collège de France. Trad. Ivone C. Benedetti. São Paulo: WMF Martins Fontes, 2015.

FOUCAULT, Michel. Ditos e escritos: Repensar a política. Trad. Ana L. Paranhos Pessoa. Rio de Janeiro: Forense Universitária, 2013. v. 6. p. 31-33.

FOUCAULT, Michel. O corpo utópico, Asheterotopias. Trad. Salma Tannus Muchail. São Paulo: n-1 Edições, 2013a.

FOUCAULT, Michel. Ditos e escritos: Arte, epistemologia, filosofia e história da medicina. Trad. Vera Lucia Avellar Ribeiro. Rio de Janeiro: Forense Universitária, 2011. v. 7. p. 184-191.

FOUCAULT, Michel. Ditos e escritos: Arte, epistemologia, filosofia e história da medicina. Trad. Vera Lucia Avellar Ribeiro. Rio de janeiro: Forense Universitária, 2011a. v. 7. p. 307-309.

FOUCAULT, Michel. Vigiar e punir: nascimento da prisão. Trad. Raquel Ramalhete. Petrópolis, RJ: Vozes, 2009.

FOUCAULT, Michel. Ditos e escritos: Literatura e pintura, música e cinema. Trad. Inês Autran Dourado Barbosa. 2. ed. Rio de Janeiro: Forense Universitária, 2009a. v. 3. p. 411-422.

FOUCAULT, Michel. O poder psiquiátrico: curso no Collège de France (1973-1974). Trad. Eduardo Brandão. São Paulo: Martins Fontes, 2006.

FOUCAULT, Michel. Em defesa da sociedade: curso no Collège de France (1975-1976). Trad. Maria Ermantina Galvão. São Paulo: Martins Fontes, 2005.

FOUCAULT, Michel. A verdade e as formas jurídicas. Trad. Roberto Cabral de Melo Machado, Eduardo Jardim Morais. 3. ed. Rio de Janeiro: Nau, 2005a.

FOUCAULT, Michel. Microfísica do poder. Trad. Roberto Machado. 19. ed. Rio de Janeiro: Edições Graal, 2004. p. 99-111.

FOUGAULT, Michel. Microfísica do poder. Trad. Roberto Machado. 19. ed. Rio de Janeiro: Edições Graal, 2004a. p. 113-128.

FOUCAULT, Michel. Microfísica do poder. Trad. Roberto Machado. 19. ed. Rio de Janeiro: Edições Graal, 2004b. p. 209-228.

FOUCAULT, Michel. Ditos e escritos: Estratégia, poder-saber. Trad. Vera Lucia Avellar Ribeiro Rio de Janeiro: Forense Universitária, 2003, v. 4, p. 61-68.

FOUCAULT, Michel. Ditos e escritos: Estratégia, poder-saber. Trad. Vera Lucia Avellar Ribeiro. Rio de Janeiro: Forense Universitária, 2003a, v. 4, p. 131-145.

FOUCAULT, Michel. Ditos e escritos: Estratégia, poder-saber. Trad. Vera Lucia Avellar Ribeiro. Rio de Janeiro: Forense Universitária, 2003b, v. 4, p. 317-322.

BATISTA, Fabio. Foucault e as heterotopias: espaço, poder-saber. Griot : Revista de Filosofia, Amargosa - BA, v.20, n.2, p.116, junho, 2020. 
FOUCAULT, Michel. Ditos e escritos: Arqueologia das ciências e História dos sistemas de pensamento. Trad. Elisa Monteiro. Rio de janeiro: Forense Universitária, 2000, v. 2, p. 307-334. FOUCAULT, Michel. Ditos e escritos: Arqueologia das ciências e História dos sistemas de pensamento. Trad. Elisa Monteiro. Rio de Janeiro: Forense Universitária, 2000a, v. 2, p. 335351.

FOUCAULT, Michel. História da sexualidade II: o uso dos prazeres. Trad. Maria Thereza da Costa Albuquerque. 8. ed. Rio de Janeiro: Edições Graal, 1998.

FOUCAULT, Michel. Quest-ce que la critique? [Critique et Aufklärung]. Bulletin de la Société Française Philosophie, 84 ${ }^{\circ}$ annés, n. 2, Avril-Juin 1990.

FOUCAULT, Michel. História da loucura na Idade Clássica. Trad. José Teixeira Coelho Netto. São Paulo: Perspectiva, 1978.

GALLO, Silvio. Possibilidades e linhas de fuga: a invenção de escolas outras no dia a dia. REP's - Revista Even. Pedagóg. Formação de Professores e Desafios da Escola no Século XXI. Sinop, v. 7, n. 2 (19. ed.), p. 994-1003, jun./jul. 2016.

GENIS, Andrea Díaz. La formación humana desde una perspectiva filosófica: inquietud, cuidado de sí y de losotros, autoconocimiento. Buenos Aires: Biblos, 2015.

HAN, Byung-Chul. Psicopolítica: neoliberalismo e novas técnicas de poder. Trad. Miguel Serras Pereira. Lisboa: Relógio D’Água, 2015.

KANT, Immanuel. O conflito das faculdades. Trad. Artur Morão. Lisboa: Edições 70, 1993.

MENDES, Igor. A pequena prisão. São Paulo: n-1 edições, 2017.

POMBO, Rocha. No hospício. Curitiba: Prefeitura Municipal de Curitiba, 1996.

Autor(a) para correspondência: Fabio Batista, Rua da Faculdade, 645 - Jd. Santa Maria, 85903-000, Toledo - PR, Brasil.fabiobatista1985@bol.com.br 